\title{
Human African Trypanosomiasis and challenges to its control in Urambo, Kasulu and Kibondo Districts, western Tanzania
}

\author{
I.I. MALELE ${ }^{*}$, S.N. KIBONA ${ }^{2}$, L.E. MATEMBA ${ }^{2}$, K. SAHANI'², J. SWILLA ${ }^{2}$, C.D. MWALIMU ${ }^{3}$, \\ B.K. MAYALA ${ }^{4}$, E. KIMARO ${ }^{5}$, C. MSUMARY ${ }^{6}$ and R.B. KALINGA ${ }^{3}$ \\ ${ }^{1}$ Tsetse E Trypanosomosis Research Institute, P.O. Box 1026, Tanga, Tanzania \\ ${ }^{2}$ Tabora Medical Research Centre, P. O. Box 482, Tabora, Tanzania \\ ${ }^{3}$ Ministry of Health and Social Welfare, P.O. Box 9083, Dar es Salaam, Tanzania \\ ${ }^{4}$ National Institute for Medical Research, P.O. Box 9653, Dar es Salaam, Tanzania \\ ${ }^{5}$ Tropical Pesticide Research Institute, P.O. Box 3024, Arusha, Tanzania \\ ${ }^{6}$ Muhimbili National Hospital, P.O. Box 65001, Dar es Salaam, Tanzania
}

\begin{abstract}
A study was carried out to determine the prevalence and management of Human African Trypanosomiasis (HAT) in Urambo, Kasulu and Kibondo districts of western Tanzania. Parasitological surveys for trypanosome and other blood parasites were conducted in selected villages. Interviews with health workers were conducted to explore facility capacity to diagnose and manage HAT. Community knowledge on tsetse and availability of trypanocidal drugs was explored. Results showed that, although health facility records showed HAT is an important public health problem in the three districts, typanosomes were found in $0.6 \%$ of the examined individuals in Urambo district only. Malaria parasites with a prevalence of $12.1 \%, 19.7 \%$ and $9.7 \%$, in Urambo, Kibondo and Kasulu, respectively were detected in blood samples from the same individuals examined for trypanosomes. There was poor capacity for most of the health facilities in the diagnosis, treatment and control of HAT. In both districts, communities were knowledgeable of the tsetse identity $(82.4 \%)$ and had experienced tsetse bites $(94 \%)$. The majority $(91.4 \%)$ of the community members knew that they were at risk of acquiring HAT. However, only $29 \%$ of the respondents knew that anti-trypanocidal drugs were readily available free of charge from health care facilities. Late treatment seeking behaviour was common in Kasulu and Urambo districts. In conclusion, health facilities in western Tanzania are faced with problems of poor capacity to diagnose and manage HAT and that treatment seeking behaviour among the communities at risk is poor. Efforts should be made to strengthen the capacity of the health facility to handle HAT cases and health education to the population at risk.
\end{abstract}

Key words: Human African Trypanosomiasis, diagnosis, control, Tanzania

\section{Introduction}

Human African Trypanosomiasis (HAT) or sleeping sickness is a vector-borne parasitic disease caused by trypanosomes and transmitted by tsetse flies of the genus Glossina (Buxton, 1955). In Tanzania, like in Southern and other East African countries, Trypanosoma brucei rhodesiense is the only form of the disease known to occur (Kilama et al., 1981; Stich et al., 2002). Tsetse flies infest much of the sub-Saharan Africa (in vegetations by rivers and lakes, gallery forests and wooded savannah) (Ford \& Katondo, 1997). About two-thirds of Tanzania is home to the tsetse fly and that over 4 millions people living in rural areas are at risk of contracting HAT. Only less than $1 \%$ of people that are at risk of infection are under regular medical surveillance (Komba et al., 1997). The rural populations whose livelihoods depend on agriculture, fishing, animal husbandry or hunting are the most exposed to the tsetse bites.

HAT is endemic in about $10 \%$ of the districts in Tanzania. It is estimated that 4-5 million
Tanzanians are at risk of the disease (Kibona et al., 2006). Available data indicate that between 1996 and 2005, a total of 2571 cases of HAT were reported in Tanzania (Kasulu $=40.4 \%$, Kibondo $=35.3 \%$, Urambo $=16.1 \%)$. Other affected districts include Babati, Monduli, Hanang, Nkasi, Mpanda and Chunya (Ministry of Health, unpubl.).

In HAT cases, it is important that diagnosis be made as early as possible in order to preclude the onset of irreversible neurological disorders (Dumas \& Bisser, 1999) and prevent transmission. Nonetheless, case detection is difficult and requires major human, technical and material resources, which are inadequate in most health facilities in the HAT endemic districts in Tanzania.

One of the major constraints in HAT control in Tanzania is lack of information regarding the actual extent of the disease in the country. This among other factors has been attributed by a week disease surveillance system, poor diagnostic capability and lack of trained staff. While vector control is necessary for the reduction of human

\footnotetext{
* Correspondence: Dr. Imna Malele; E-mail: malele2i@yahoo.com
} 
vector contact and thus reduction in transmission of the disease; disease surveillance is imperative for early and effective diagnosis.

This study was carried out to determine the current status of HAT in western Tanzania following its resurgence in recent years (Ministry of Health, unpubl.). Specifically, this study aimed at obtaining information on the status of HAT in endemic districts of Urambo, Kasulu and Kibondo in western Tanzania with major emphasis on the diagnostic and case management capability of health care facilities and community knowledge of the disease and availability of treatment.

\section{Materials and Methods}

\section{Study area and population}

This study was carried out in Kasulu, Kibondo and Urambo districts in western Tanzania. Kasulu $\left(4^{\circ}, 30^{\prime} \mathrm{S}, 30^{\circ}, 00^{\prime}\right)$ and Kibondo $\left(4^{\circ}, 07^{\prime} \mathrm{S}, 31^{\circ}, 00^{\prime} \mathrm{E}\right)$ districts are in Kigoma region and the districts are served by Malagarasi river valley which is a typical tsetse fly belt with forest, game reserve and open grassland. The population in this area is for the most part concentrated in the villages on the Kigoma-Kibondo trunk road. HAT infections are contracted mainly by those hunting, fishing, timbering, collecting honey, herdsmen and those travelling in the bush on other occasions in search for basic necessities of life. Urambo district $\left(4^{\circ}\right.$, $45^{\prime} \mathrm{N}, 32^{\circ}, 00^{\prime} \mathrm{E}$ ) is in Tabora region and has similar characteristics as those of Kibondo and Kasulu districts.

\section{Parasitological surveys}

Eight villages were conveniently selected for survey in Urambo district, while in Kibondo and Kasulu, six and five villages were covered, respectively. In each selected village, 50-100 people preferably those with forest related activities which include honey gathering, timbering, charcoal works, fisheries, hunting, herdsmen and as well as those with clinical presentation of the disease were actively screened and examined microscopically for trypanosomes and other blood parasites. Case detection was also conducted by actively screening people in the community especially those with activities that make them more prone to tsetse bites and hence the infection.

Peripheral blood was collected aseptically and investigated using blood slide stained by Field's stain A and B, then dried in the open space before detection was done using microscope under the magnification of $x 100$. Confirmatory test for trypanosomes was done using Haematocrit Centrifugation Technique.

\section{In-depth interviews}

Face-to-face in-depth interviews were conducted to health workers including the district medical officers, in-charges of health facilities and laboratory technicians/ assistants of Kasulu, Kibondo and Urambo district hospitals and Kaliua Health Centre. Other health facilities workers were from Lumbe, Igagala and Usinge (Urambo), Busunzu and Kumhansha (Kibondo) and Kifura (Kasulu). Information was explored to whether the medical personnel and health facilities were able to manage cases of HAT. Medical personnel were also asked about the treatment seeking behaviour of the community. Information was sought on availability of equipment and supplies for laboratory diagnosis of HAT.

Community in-depth interviews were also conducted to explore their knowledge on tsetse flies, experience in tsetse bites, the risk associated with tsetse flies, and availability of drugs for HAT treatment.

\section{Results}

Blood samples from a total of 1087 individuals were examined for the presence of trypanosome species. In Kaliua, Urambo, only $3(0.6 \%)$ people were found to be positive with trypanosomes parasites. We did not intend to screen for malaria parasites, however, they were observed during HAT screening. Although only three HAT cases $(2.9 \%)$ were detected through active case detection in Usinga village, passive case detection identified a total of 34 cases from Lumbe, Usinga, Kangeme and Igagala in Kaliua Division of Urambo district. Malaria cases were actively detected in each village surveyed. Malaria parasitaemia rates were $12.12 \%$ in Urambo, $19.7 \%$ in Kibondo and $9.7 \%$ in Kasulu district (Table 1).

All in-charges of Health Centres and Dispensaries at Kaliua, Lumbe, Igagala, Usinge, Busunzu, Kumhansha and Kifura admitted that HAT was one of the major health problems in their catchment areas. Similar opinions were given by laboratory personnel at the district hospitals. However, health workers in the refugee camps (Nyarugusu, Nduta and Mtabila) were of the opinion that the disease was not a major public problem.

All the three District Medical Officers (DMOs) admitted to receive cases of HAT at different stages of the disease. The DMO for Kibondo reported that patients were seeking medical attention at an early stage of the disease. In Kasulu and Urambo the DMO reported that patients in their respective districts were seeking medical attention mostly at the late stages of the disease, because they usually attend to traditional 
healers or resort to the use of antimalarial drug against clinical fever. Records from the district reports showed that 9, 5, and 4 villages were mostly affected in Kibondo, Kasulu and Urambo districts, respectively (Table 2 ).

It was observed that Kasulu district hospital was also receiving patients from neighbouring districts of Kibondo (Busunzu village) and Urambo (Usinge) and Kigoma rural
(Basanza and Nguruka).

According to all the three DMOs, antitrypanocidal drugs were available to patients, freeof charge at the district hospitals. The districts were obtaining their drug supplies from the Medical Store Department of the Ministry of Health or the World Health Organization through the National Institute for Medical Research. The responses from the health workers are summarised in Table 3.

Table 1: Prevalence of trypanosome and Plasmodium falciparum parasites among people in Urambo, Kibondo and Kasulu districts

\begin{tabular}{|c|c|c|c|c|}
\hline District & Village & No. screened & Trypanosome +ve & Malaria +ve \\
\hline \multirow[t]{8}{*}{ Urambo } & Lumbe & 125 & 0 & $8(6.4 \%)$ \\
\hline & Kangeme & 101 & 0 & $3(2.9 \%)$ \\
\hline & Usinga & 104 & $3(2.9 \%)$ & $13(12.5 \%)$ \\
\hline & Usinge & 76 & 0 & $20(19.9 \%)$ \\
\hline & Maboha & 32 & 0 & $6(18.75 \%)$ \\
\hline & Kombe & 39 & 0 & $5(12.82 \%$ \\
\hline & Igagala & 18 & 0 & $5(27.7 \%)$ \\
\hline & Total & 495 & $3(0.6 \%)$ & $60(12.12 \%)$ \\
\hline \multirow[t]{7}{*}{ Kibondo } & Kifura & 67 & 0 & $13(19.4 \%)$ \\
\hline & Kisogwe & 77 & 0 & $21(27.3 \%)$ \\
\hline & Nyamkwi & 50 & 0 & $9(18 \%)$ \\
\hline & Kigendeka & 50 & 0 & $4(8 \%)$ \\
\hline & Kumbanga & 43 & 0 & $10(23.3 \%)$ \\
\hline & Kumhasha & 28 & 0 & $5(17.9 \%)$ \\
\hline & Total & 315 & 0 & $62(19.7 \%)$ \\
\hline \multirow[t]{6}{*}{ Kasulu } & Makere & 62 & 0 & $6(9.7 \%)$ \\
\hline & Nyamidaho & 65 & 0 & $5(7.7 \%)$ \\
\hline & Mvugwe & 54 & 0 & $4(7.4 \%)$ \\
\hline & Kagera Nkanda & 53 & 0 & $8(15.1 \%)$ \\
\hline & Mvinza & 43 & 0 & $4(9.3 \%)$ \\
\hline & Total & 277 & 0 & $27(9.7 \%)$ \\
\hline
\end{tabular}

Table 2: Villages with most cases of HAT patients in Kibondo, Kasulu and Urambo Districts

\begin{tabular}{lll}
\hline Kibondo District & Kasulu District & Urambo District \\
\hline Busunzu & Kagera-Nkanda & Usinge \\
Kifura & Mvinza & Kangeme \\
Nyankwi & Nyamidaho & Kombe \\
Kisogwe & Makere & Usinga \\
Nyaruyoba & Mvungwe & \\
Kigaga & & \\
Kigendeka & & \\
Kabuya & & \\
Kumshindwi & & \\
\hline
\end{tabular}


Table 3: Responses on the situation as regards to HAT management according to health workers in Urambo, Kibondo and Kasulu districts

\begin{tabular}{|c|c|c|c|c|}
\hline \multirow{2}{*}{ Type of service/supplies } & \multicolumn{4}{|c|}{ District } \\
\hline & $\begin{array}{l}\text { Urambo } \\
\text { District } \\
\text { Hospital }\end{array}$ & $\begin{array}{l}\text { Urambo } \\
\text { Kaliua Health } \\
\text { Centre* }\end{array}$ & $\begin{array}{l}\text { Kibondo } \\
\text { District } \\
\text { Hospital }\end{array}$ & $\begin{array}{l}\text { Kasulu } \\
\text { District } \\
\text { Hospital }\end{array}$ \\
\hline Case management & Not capable & Capable & Capable & Capable \\
\hline $\begin{array}{l}\text { Treatment seeking } \\
\text { behaviour }\end{array}$ & Late & Late & Early & Late \\
\hline Human resource & Inadequate & Inadequate & Inadequate & Inadequate \\
\hline Laboratory supplies & Inadequate & Inadequate & Adequate & Adequate \\
\hline Laboratory space & Inadequate & Inadequate & Inadequate & Inadequate \\
\hline
\end{tabular}

In-charges of laboratories at district hospitals in Kibondo and Kasulu reported to have sufficient laboratory facilities and supplies for diagnosing parasitic infections including trypanosomes. In both districts, blood slides for trypanosomes were done on routine basis. However, in both district hospitals, laboratory space was a limiting factor in providing adequate services. Moreover, health workers in Kibondo and Kasulu hospitals complained of lack of continuing education and refresher course to up-date their knowledge and skill on trypanosomiasis.

Of the four health centres surveyed, only Kaliua Health Centre (in Urambo district) had the because their daily socio-economic activities expose them to tsetse bites and hence the disease. It was also noted that some of the people could recognize clinical presentation of the disease. Most people interviewed were not aware that drugs are given free of charge. There was a high tendency for some sick people to attend to traditional healers before consulting conventional health facilities. This appeared to be the factor behind the late stage phase increase of the disease. Generally local people had knowledge that tsetse flies were responsible for transmission of trypanosomiasis and they were willing to participate in tsetse control programmes (Table 4).

Tables 4: Percent of respondents with knowledge on tsetse fly and availability of drugs

\begin{tabular}{lllll}
\hline Knowledge on & Urambo & Kibondo & Kasulu & Average \\
\hline Tsetse identity & 98.2 & 61.5 & 81.6 & 80.4 \\
Having bitten by tsetse & 98.8 & 90.1 & 93.2 & 94.0 \\
Risk associated with tsetse flies & 84.6 & 96.4 & 93.3 & 91.4 \\
Availability of free drugs & 35.5 & 40.6 & 13.0 & 29.7 \\
Total interviewee & 169 & 122 & 136 & - \\
\hline
\end{tabular}

capacity to diagnose, confirm and treat HAT. This was the only facility with the capacity in Urambo district. However, most of their patients were seeking medical attention at a late stage of the disease. Interestingly, in Kibondo and Kasulu while all refugee camps health facilities had the capacity to diagnose trypanosomes, the public-owned health facilities lacked such capacity and referred suspected cases to Kibondo and Kasulu District Hospitals. Health workers in the surveyed health centres and dispensaries reported lack of antitrypanocidal drugs.

Community interviews showed that most people were able to associate the presence of tsetse and sleeping sickness. Males were at higher risk of contracting the disease than females. This was
On average $82.4 \%$ of the respondents in the three districts had seen and could recognise a tsetse fly; 94.0\% had experienced a bite from tsetse fly; $91.4 \%$ knew that they were at risk of acquiring tsetseborne infections and only 29.\% were aware that free drugs were available at health facilities. The majority of the respondents reported that the drugs were sold either at the health facilities or by drug vendors.

\section{Discussion}

HAT is sometimes mistakenly for malaria due to the fact that early phase of the disease entails bouts of fever, headaches, pains in the joints and itching. Thus with the high incidences of malaria in western 
Tanzania, HAT is mistakenly treated as malaria. During the survey only $0.6 \%$ of the people were found positive to trypanosomes. The co-infection between malaria and HAT appeared to be very common in the districts. However, further investigation is recommended to assess its true magnitude. Other haemoparasites such as Borrelia duttoni species have been reported to cause febrile illness in malaria-endemic areas in Tanzania and hence is another important differential diagnosis for fever (Talbert, 2005). It is therefore important that laboratory diagnoses are always made to confirm the disease before treatment is prescribed. It has already be observed that sleeping sickness affects remote and rural areas of sub-Saharan Africa where health systems are least effective, or nonexistent. In other parts of the tsetse-infested belt, HAT spreads with socio-economic problems such as political instability, displacement of populations, war and poverty (Moore et al., 2001; Ekwanzala et al., 1996; Stanghellini \& Josenando, 2001; Smith et al., 1998).

Trypanosomiasis cases are only managed at few health facilities, which are also understaffed. Critical understaffing was observed in Urambo district at Kangeme, Kombe, Usinga, Ulindwanoni and Tuombe Mungu dispensaries, which had no trained health personnel (data not shown). Lack of capacity to diagnose and manage HAT in most health facilities force sleeping sickness patients to travel long distances $(15-110 \mathrm{~km})$ to seek medical attention at the district hospitals or Kaliua Health Centre. Most of the roads in these districts are impassable during the rainy season. These factors are likely to be among the main reasons as to why most people seek medical attention when the disease has reached the late stage. It is important that all health facilities in this part of Tanzania, are well equipped with adequate qualified staff, equipment, laboratory supplies and drugs to manage HAT cases. Improving laboratories is vital in any disease surveillance system as it will provide an early warning in case of an outbreak (Mghamba et al., 2005).

In Tanzania, HAT is successfully treated with suramin; but treatment of late-stage of the disease, where trypanosomes have invaded the central nervous system, depends exclusively on melarsoprol. The regimen for HAT is strict and hard to apply. In short, most drugs are old, difficult to administer in poor conditions and by no means always successful. Early diagnosis of the disease, which would guarantee low-risk treatment on an outpatient basis, can rarely be achieved (Stich et al., 2002). Moreover, there is great evidence for resistance to the HAT drugs that have been in continuous use for at least over 5 decades (Croft et al., 1997; Kibona et al., 2006).
The disease can be successfully controlled by a combination of approaches including active case finding, treatment of patients and vector control (WHO, 1998). Detection of the disease calls for major human and material resources, such as wellequipped health facilities and qualified staff. Because such resources are lacking, most people with sleeping sickness die before they can ever be diagnosed (Bailey \& Smith, 1992).

Health education should be provided to all communities in villages where HAT is endemic. Health education should emphasise the need for early reporting of any trypanosomiasis suspected case to the health facility to avoid the late stage of the disease; which is difficult to treat. Communities living adjacent to tsetse-infested forests should be educated on the risks associated with forest activities; and initiations of community based tsetse control programs to reduce the tsetse - man contact. However, this can only be possible, if alternative income generating activities are introduced in HAT endemic areas. In conclusion, HAT is a public health problem in western Tanzania. Efforts should be made to strengthen case management and vector control programs in all endemic villages.

\section{Acknowledgements}

We acknowledge the support received form the Regional and District Medical Officers of the Kigoma and Tabora. This study received financial assistance from the Ministry of Health, Tanzania.

\section{References}

Bailey, J.W. \& Smith, D.H. (1992). The use of the acridine orange QBC technique in the diagnosis of African trypanosomiasis. Transactions of the Royal Society of Tropical Medicine and Hygiene 86, 630.

Buxton, P.A. (1955). The Natural History of Tsetse flies: An Account of the Biology of the Genus Glossina (Diptera). H.K. Lewis \& Co., London.

Croft, S., Urbina, J.A. \& Brun, R. (1997). Trypanosomiasis and Leishmaniasis: Chemotherapy of Trypanosomiasis and Leishmaniasis. In: G. Hide, J.C. Mottram, G.H. Coombs and P.H. Holmes (eds.). Biology and Control.

Dumas, M. \& Bisser, S. (1999) Clinical aspects of human African trypanosomiasis. In: Dumas M, Bouteille B, Buguet A, eds. Progress in Human African Trypanosomiasis, Sleeping Sickness. Paris: Springer-Verlag.

Ekwanzala, M., Pepin, J., Khonde, N., Molisho, S., Bruneel, H. \& De Wals, P. (1996) In the heart of darkness: sleeping sickness in Zaire. Lancet 348,1427-1430. 
Ford, J. \& Katondo, K.M. (1977). Maps of tsetse fly (Glossina) distribution in Africa 1973, according to sub-generic groups at a scale of 1:5,000,000. Bulletin of Animal health and Production in Africa 15, 187-193.

Kibona, S.N., Matemba, L, Kaboya, J.S. \& Lubega, G.W. (2006) Drurg-resitance of Trypanosoma b. rhodesiense isolates from Tanzania. Tropical Medicine and International Health 11, 144-155.

Kilama, W., Mtera, K.N.M. \& Paul, R.K. (1981). Epidemiology of Human Trypanosomiasis in Tanzania. Proceedings of the 17the Meeting of the International Scientific Council for Trypanosomiasis Research and Control. Arusha Tanzania. OAU / STRC Publications 112, 187193.

Komba, E.K., Kibona, S.N., Ambwene, A.K., Stevens, J.R. \& Gibson, W.C. (1997) Genetic diversity among Trypanosoma $b$. rhodesiense isolates from Tanzania. Parasitology 115, 571579.

Mghamba, J.M., Mmbuji, P.K, Mboera, L.E.G., Mgaya, V., Senkoro, K.P. \& Cavallaro, K. (2005). Improving laboratory surveillance and networking: a challenge to the Tanzania Integrated Disease Surveillance and Response strategy. Proceedings of the 20th Annual Joint Scientific Conference and Silver
Jubilee of the National Institute for Medical Research, March 1 - 4, 2005, AICC Arusha Tanzania

Molyneux, D.H. \& Pentreath, V. (1996). African trypanosomiasis in man. Manson's Tropical Diseases. G.C. Cook. London, W.B. Saunders Company Ltd.: 1171-1196.

Smith, D.H., Pepin, J. \& Stich, A. (1998) Human African trypanosomiasis: an emerging public health crisis. British Medical Bulletin 54, 341355.

Stanghellini, A. \& Josenando, T. (2001) The situation of sleeping sickness in Angola: a calamity. Tropical Medicine and International Health 6, 330-334.

Stich, P., Abel, M. \& Krishna, S. (2002) Human African Trypanosomiasis: Clinical Review. British Medical Journal 325, 203-206.

Talbert, A. (2005) Tick-borne relapsing fever in Mvumi Hospital, Tanzania: a retrospective study of laboratory data between 1997 and 2002. Tanzania Health Research Bulletin 7, 4042.

WHO (1998) Control and Surveillance of African Trypanosomiasis. WHO Technical Report Series 881, Geneva. World Health Organization. 